\title{
The Exchange-Free Technique: A Novel Technique for Enhancing Surpass Flow Diverter Placement
}

\begin{abstract}
Background: Following flow diverter placement, approximately $20 \%$ of intracranial aneurysms remain as residual aneurysms at 1 year. Device malapposition is a cause of residual aneurysms after flow diversion. We present a new and straightforward technique (exchange-free technique [EFT]) to enhance apposition of the surpass flow diverter (SFD), the only over-the-wire flow diverter currently available. Materials and Methods: We deployed laser-cut mini stents through the inner deployment catheter of the SFD. This maneuver was performed simply by withdrawing the micro-guidewire from its lumen and replacing it with a mini-stent (stents deliverable through microcatheters with inner diameter of 0.0165 inches), without a need to re-cross the deployed SFD or an exchange maneuver. All aneurysms in which this technique was utilized were retrospectively reviewed. Results: Twenty-eight patients (20 females) with 30 treated aneurysms were identified. The mean aneurysm diameter was $10.2 \pm 6.6 \mathrm{~mm}$. Technical success rate was $96.6 \%$ (29/30 aneurysms). There was no mortality or permanent morbidity related to the procedures. Except for the patient treated for an iatrogenic, surgery-related internal carotid artery pseudoaneurysm who died secondary to consequences of multiple surgeries, no cases of mortality or permanent morbidity were noted. Complete aneurysm occlusion rates were $78.2 \%, 82.1 \%$, and $95.2 \%$ at $0-3,3-6$, and 9-12 months, respectively. None of the patients were re-treated. Conclusion: EFT is a simple and fast technique which was not associated with adverse effects in our series. The higher aneurysm obliteration rate obtained with EFT is probably the result of better wall apposition of the SFD.
\end{abstract}

Keywords: Aneurysm, endovascular treatment, flow diversion, flow diverter, stent

\section{Introduction}

Flow diverters are safe and effective in the treatment of cerebral aneurysms, including wide necked and fusiform aneurysms which have high recanalization rates with coiling. Complete aneurysm occlusion rates for different flow diverters in device-specific studies are reported to be between $56 \%$ and $71.4 \%$ at 3 months, ${ }^{[1-3]} 66.6 \%-75 \%$ at 6 months, ${ }^{[1,3-6]}$ and $77.8 \%-86.6 \%$ at 1 year follow-up. ${ }^{[1,2,4,5]}$ A variety of techniques have been proposed to increase the efficacy of flow diverters. ${ }^{[7]}$ The most popular of these is adjunctive coiling and to a lesser extent, a combination of a flow diverter with the woven endobridge device. ${ }^{[8,9]}$ There are few reports about combined usage of stents with flow diverters, ${ }^{[10-12]}$ and recently, it has been shown that this technique reduces the time needed for complete aneurysm occlusion. ${ }^{[13]}$ In this article, we describe a new technique, the exchange-free technique (EFT) that

This is an open access journal, and articles are distributed under the terms of the Creative Commons Attribution-NonCommercial-ShareAlike 4.0 License, which allows others to remix, tweak, and build upon the work non-commercially, as long as appropriate credit is given and the new creations are licensed under the identical terms.

For reprints contact: WKHLRPMedknow_reprints@wolterskluwer.com not only enhances the wall apposition of the surpass flow diverter (SFD) but also, in selected cases, allows us to anchor the landing zones by pinning the device by means of a laser-cut stent directly placed through the unique delivery system of the SFD. EFT provides a fast and easy way to appose and pin the Surpass device without a need to re-cross the deployed flow diverter.

\section{Materials and Methods}

\section{Patients}

This retrospective study was approved by the Ethics Committee of our University Hospital. Patient consent was not required since the study involved only a retrospective chart review of anonymous patient data. We evaluated all of our patients treated with a flow diverter between August 2015 and April 2018 and identified the patients who were treated with a Surpass device. Those patients in whom another stent

How to cite this article: Ocal $O$, Arat $A$. The exchange-free technique: $A$ novel technique for enhancing surpass flow diverter placement. Asian J Neurosurg 2020;15:620-6.

Submitted: 31-Dec-2019 Accepted: 18-Apr-2020

Revised: 26-Feb-2020 Published: 28-Aug-2020

\section{Osman Ocal, Anıl Arat}

Department of Radiology, Faculty of Medicine, Hacettepe University, Ankara, Turkey

\section{Address for correspondence: \\ Prof. Anıl Arat, \\ Department of Radiology, Faculty of Medicine, Hacettepe \\ University, Hacettepe Mh. 06230 Ankara, Turkey. \\ E-mail: anilarat@hotmail.com}

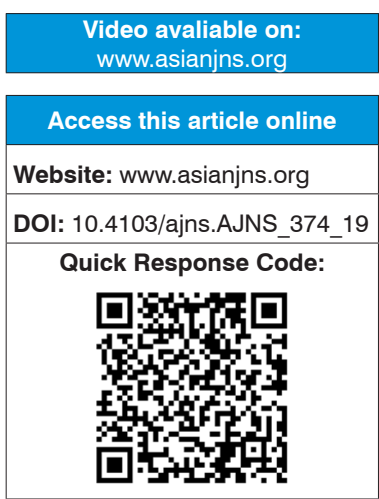


was deployed during the same session was determined. Patients were excluded if a stent was deployed via a dedicated microcatheter (any other catheter except the inner catheter of Surpass delivery system) to appose the SFD (the "apposing stent"). A total of 28 patients with a mean age of $48.5 \pm 15.5$ (range 6-84 years) were identified. The age, sex, comorbidities, aneurysm location, size of the aneurysm, platelet inhibition level, adverse events and aneurysm occlusion of these patients were analyzed.

\section{Devices}

The SFD is a recently introduced flow diverter made of a cobalt-chromium alloy with integrated platinum wires to enhance visibility. The mesh density of the device is kept constant by increasing the number of wires as the diameter of the stent increases (e.g., 72 wires in $3-4 \mathrm{~mm}$ vs. 96 wires in $5 \mathrm{~mm}$ diameter). Its porosity is similar to its counterparts, whereas its mesh density is higher with 20-32 pores $/ \mathrm{mm}^{2}$. The Surpass device is preloaded at the distal end of the delivery system, which is composed of inner (pusher) and outer (delivery) catheters. The delivery system of the Surpass device is a slightly larger version of the delivery system used in the Wingspan Stent (Stryker Neurovascular, Kalamazoo, MI, USA) in which the Wingspan stent is "sandwiched" between the outer delivery catheter and the approximately $2 \mathrm{~F}$ inner delivery catheter. The outer diameter of the outer delivery catheter is $3.9 \mathrm{~F}$ at the proximal end and $3.7 \mathrm{~F}$ at the distal end. The inner delivery catheter, which we utilized in this study for stenting, has an outer diameter of approximately $2 \mathrm{~F}$, an inner diameter of 0.017 inch and is advanced over 0.014 inch microwire. The Surpass device is confined between the inner and outer catheters. It is deployed by unsheathing the outer $3.7 \mathrm{~F}$ catheter over the inner catheter, which is kept in place on the microwire. That is, there is no distal delivery wire. The device expands and conforms to the shape of the vasculature as it exits the lumen of the outer catheter. Meanwhile, the inner catheter moves distally over the microwire which is stationary. This delivery system is unique to SFD.

The Neuroform Atlas stent (Stryker, Kalamazoo, MI, USA) is a self-expanding, open cell, nitinol stent available in 2.5-4.5 mm diameters and $15-30 \mathrm{~mm}$ lengths. It has three radiopaque markers on each end. The stent is preloaded on the stent delivery wire and protected by an introducer sheath. All sizes of the Atlas stent can be delivered through a microcatheter with a 0.0165 -inch inner diameter.

The Acclino stent (Acandis, Pforzheim, Germany) is a self-expanding, closed cell, nitinol stent. It also has three radiopaque markers on each end and is available in 3.5, 4.5 , and $6.5 \mathrm{~mm}$ diameters and $15-35 \mathrm{~mm}$ lengths. While the stents with 3.5 and $4.5 \mathrm{~mm}$ diameters are deliverable through microcatheters with a 0.0165 -inch inner diameter, the $6.5 \mathrm{~mm}$ diameter stents require microcatheters with a 0.021-inch inner diameter.

\section{Antiplatelet therapy}

Unruptured patients were started on a $300 \mathrm{mg}$ acetylsalicylic acid and $75 \mathrm{mg}$ clopidogrel (or $10 \mathrm{mg}$ prasugrel) regimen at least 5 days before the intervention. Two patients, who were treated in the subacute phase of subarachnoid hemorrhage, were given a loading dose of $300 \mathrm{mg}$ clopidogrel and $300 \mathrm{mg}$ of aspirin 1 day before the procedure. One patient with an iatrogenic pseudoaneurysm was administered IV tirofiban during the procedure. The infusion was continued over the next $24 \mathrm{~h}$, after which the patient was loaded with $300 \mathrm{mg}$ clopidogrel. All patients, including the latter three, were then kept on $75 \mathrm{mg}$ clopidogrel and $300 \mathrm{mg}$ aspirin per day for 6 months. After a 6-month digital subtraction angiography (DSA) patients were maintained only on acetyl salicylic acid. Platelet inhibition was verified according to institutional protocol by the VerifyNow assay (Accumetrics, San Diego, CA, USA). Six patients who were resistant to clopidogrel were instead placed on a $10 \mathrm{mg} /$ day prasugrel regimen.

\section{Endovascular procedure}

All treatments were performed under general anesthesia and systemic heparinization (activated clotting time $>250 \mathrm{~s}$ ) and using biplane flat panel DSA machines (Artis Zee Siemens, Erlangen, Germany). Both two-dimensional (2D) and 3D images were used to measure the parent artery and aneurysm sizes. For all procedures, a $6 \mathrm{~F}$ guiding sheath and a distal access catheter (AXS Catalyst 5; Stryker, Freemont, CA, USA or Navien; ev3 Neurovascular, Irvine, CA, USA) were advanced to the target parent artery via a femoral access. After catheterization, 2-5 $\mathrm{ml}$ of Nimodipine (Nimotop, Bayer, Newbury, Berkshire, UK, in $50 \mathrm{ml}$ saline) was infused intraarterially. The Surpass device was deployed under fluoroscopic visualization, and proper vessel apposition was assessed with angiography and if necessary, with flat detector CT with intra-arterial contrast injection [Supplementary Digital Content 1 Figures 1-7]. The Surpass device was navigated across the aneurysm neck over a 0.014 microguidewire. Once the operator decided to place a stent within the flow diverter, the system was not withdrawn and only the microwire was removed. One of the mini stents mentioned above was directly advanced within the inner delivery catheter that was already in place, with its tip distal to the flow diverter. The stent was deployed through this catheter [Figure 1, Supplemental Digital Content 2 and Video 1, Supplemental Digital Content 3]. The stent was delivered directly through the pusher (inner) catheter, without a need for performing an exchange maneuver or using another microcatheter. The mini-stents were deployed in a manner to cover the whole flow diverter so that we can obtain an enhanced opening and apposition throughout the flow diverter. At times, this was not possible because the flow diverter spanned a long segment and it was not possible cover the whole device with a single stent. In these cases, as long 


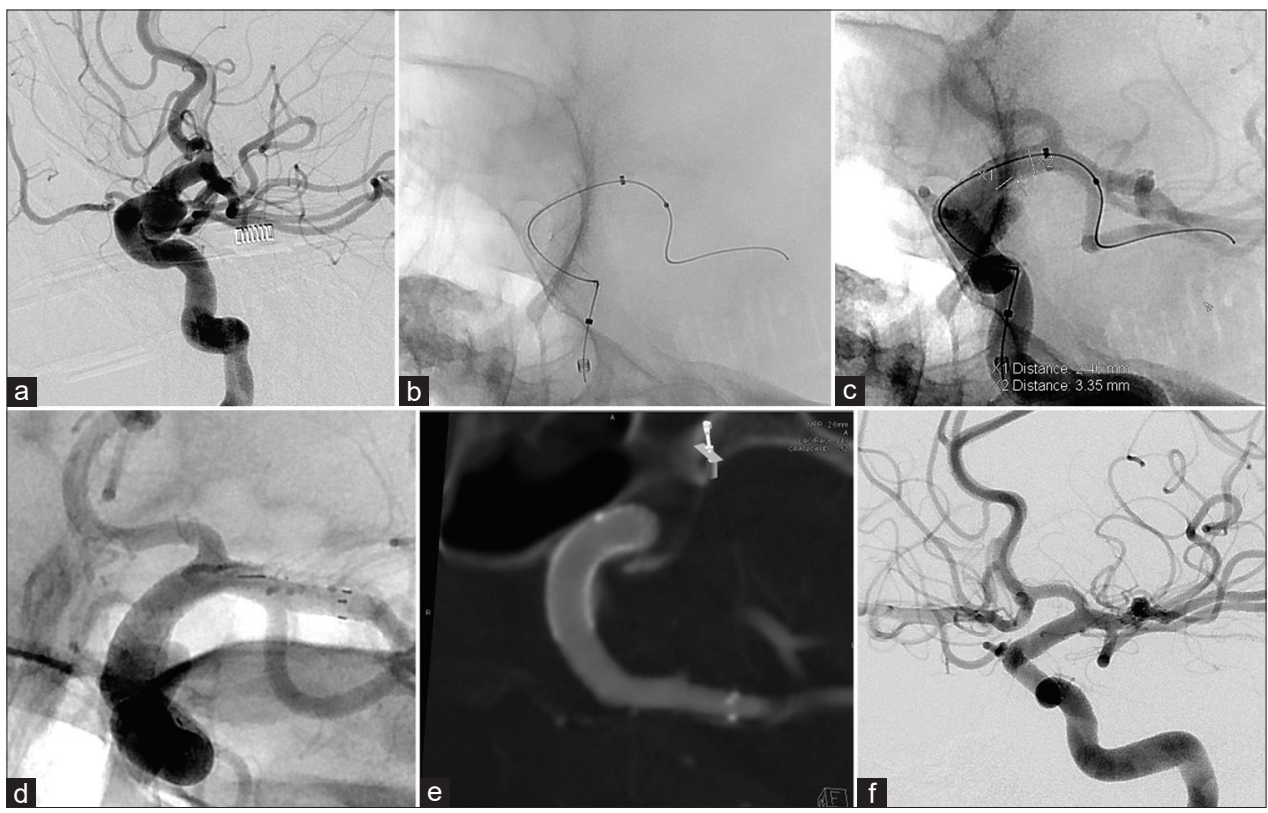

Figure 1: (a) Left internal carotid artery angiogram shows a supraclinoid aneurysm. Subtracted: Native image before (b) and after (c) contrast injection following deployment of the flow diverter show that the distal landing zone of the device is shorter than the diameter of the parent artery. (Arrow indicates distal end of the flow diverter) (d) angiogram after the deployment of a stent inside flow diverter demonstrates pinning of the device to the parent artery with good wall apposition (e) flat detector computed tomography image with intra-arterial contrast administration shows good wall apposition (f) follow-up angiogram obtained 6 months after the procedure shows complete occlusion of the aneurysm

as one end (either distal or proximal) was secure and well apposed, we opted to deploy the mini stent to cover the other end of the device which needed to be pinned by the mini stent. Follow-up angiograms and a final flat detector computed tomography (CT) were performed $30 \mathrm{~min}$ after stent deployment to check vessel wall apposition, patency of the parent vessel and intraluminal thrombus formation.

Follow-up imaging with computer tomography or magnetic resonance angiography and clinical evaluation were performed at 1-3 months. DSA was performed at 6 months. Noninvasive imaging and clinical follow-up was repeated at $9-12$ months.

\section{Results}

\section{Patient and aneurysm characteristics}

There were 30 aneurysms in 28 patients. Twenty patients $(71.5 \%)$ were female and $8(28.5 \%)$ were male. The mean aneurysm size diameter was $10.2 \pm 6.6 \mathrm{~mm}$ (range $3-30 \mathrm{~mm})$. Two of the 30 aneurysms were giant $(>25 \mathrm{~mm})$ and 12 were large $(>10 \mathrm{~mm})$. Twenty-five of $30(83.3 \%)$ aneurysms were in the anterior circulation. Of these, 15 originated from the supraclinoid segment, 6 from the cavernous segment and 3 from the ophthalmic segment and 1 from the transitional segment of the internal carotid artery (ICA). Two of the 5 posterior circulation aneurysms were in the basilar trunk, one in the basilar apex, one in the V4 segment and the other was a fusiform aneurysm extending from the V4 segment of the vertebral artery to the basilar artery. There were 23 saccular aneurysms, 5 fusiform/dissecting aneurysms, one blister aneurysm and one pseudoaneurysm secondary surgical ICA injury. Four aneurysms were recurrent. Of these, 3 had previously been treated with coiling and the other one with another flow diverter. Three of the 30 aneurysms (including one with iatrogenic pseudoaneurysm) were ruptured and treated in the subacute phase.

\section{Procedure characteristics}

Our technical success rate (deployment of the stent inside flow diverter) was $96.6 \%$ (29/30). Loading of the stent into the inner catheter at the hub required special attention as the hub was not specifically designed for the passage of stents. However, once the device passed through the hub, there was no resistance to stent navigation. The only failure was secondary to ovalization of the inner catheter at a tortuous syphon which did not allow us to push an Acclino stent further. This stent was withdrawn, the aneurysm was bypassed with an Echelon 10 microcatheter (ev3 Endovascular, Plymouth, MN, USA) and the same stent was than deployed within the flow diverter. All patients were treated with a single surpass device except one patient who needed a second device due to incomplete neck coverage with one flow diverter. In two patients for whom a $40 \mathrm{~mm}$ length Surpass device was used, two stents were needed since the currently available stents have maximum lengths of 30-35 mm, which were not long enough to cover the whole length of the long flow diverter. In 23 patients, Atlas stents were used, and in 5 patients, Acclino stents were used. In only three patients, intrasaccular embolization was performed during the same session of flow diverter placement. 
The stent was placed through the Surpass delivery system in the following situations:

1. The device was deployed along a fusiform or wide neck aneurysm, in which re-crossing of the freshly deployed device was deemed to be risky due to concerns related to stent migration into the aneurysm due to short landing zone [Figure 2, Supplemental Digital Content 2] ${ }^{[1]}$

2. After the device was deployed, it was realized that the proximal or distal landing zone was less than ideal, i.e., distance $<6 \mathrm{~mm}$ or less than the diameter of the parent artery, which is not an ideal deployment [Figure 1] ${ }^{[14,15]}$

3. The proximal or distal landing zones were around artery bends, leading to device malapposition, a situation that does not respond well to balloon angioplasty [Figure 3, Supplemental Digital Content 2] $]^{[15,16]}$

4. The distal end of the device was covering the origin of an intracranial major artery barely or partially, so that further expansion and apposition of the device would also lead to further shortening and subsequently unjailing of the specific arterial branch [Figure 4, Supplemental Digital Content 2]

5. Previously placed endovascular devices which preclude the evaluation of optimal apposition (previously placed coils or stents) [Figure 5, Supplemental Digital Content 2]. ${ }^{[17]}$

In two patients minimal clot formation was noted inside the flow diverter and successfully treated with immediate administration of a glycoprotein IIb/IIIa inhibitor. In another patient, guiding sheath related minor ICA dissection occurred during the procedure and was treated with a stent. All of the patients were discharged without neurological morbidity except the patient with surgical ICA injury.

\section{Angiographic outcome}

Except one patient, all of the patients had follow-up imaging. Two patients had only CT angiographic follow-up due to their reluctance to undergo a DSA procedure. Five patients did not receive the 3-months follow-up but did undergo the DSA procedure at 6 months. One-year follow-up was not due in 8 patients.

Complete aneurysm occlusion (100\%) was achieved in $18 / 23$ (78.2\%) aneurysms at 3 months, $23 / 28$ (82.1\%) aneurysms at 6 months, and 20/21 (95.2\%) aneurysms at 9 months to 1-year follow-up imaging. In a single patient, we were unable to appose flow diverter completely with the stent. This was because SFD foreshortened more than we expected, the Atlas stent was immediately deployed to prevent migration; however, the flow diverter remained too short to cover the neck of the aneurysm total. Another stent was not deployed due to the risk of device prolapse into aneurysm while crossing flow diverter with a catheter it segment could not cover the proximal part of the fusiform aneurysm. The patient refused further intervention and is currently being followed by MRA at 6 months' intervals without any change in the size and configuration of the residual aneurysm [Figure 2, Supplemental Digital Content 2].

No significant $(\geq 50 \%)$ stenosis within the flow diverter or fish mouthing of the device was seen. None of the patients were retreated.

\section{Complications}

None of the patients had clinically significant thromboembolic or hemorrhagic complications after discharge. The patient with iatrogenic pseudoaneurysm was brought directly to the angiography suite from the operating room where she was having a transsphenoidal surgery. The patient had a lacerated ICA for which endovascular treatment was performed. After treatment and past the acute period, the patient underwent multiple transsphenoidal surgeries due to extensive involvement of the skull base with carcinoma. The patient died 53 days after the endovascular procedure secondary to postoperative sepsis. Otherwise, there were no permanent morbidity, mortality, or bleeding complications.

\section{Discussion}

Flow diversion is an effective method for endovascular treatment of intracranial aneurysms. However, flow diversion does not lead to immediate aneurysmal occlusion and complete aneurysm occlusion rates at 6 months and 1 year are about $75 \%-85 \%{ }^{[1,2,4,5,18,19]}$ Residual aneurysms treated with flow diverters are still at a risk of rupture. Although the risk is, in general, small, it may be significant if there is residual opacification of the aneurysm dome on follow-up imaging. ${ }^{[20]}$

The factors involved in residual aneurysmal filling after flow diversion include malapposition, ${ }^{[21-26]}$ aneurysm size, ${ }^{[27]}$ length of transition zone ${ }^{[28]}$ and possibly strut thickness. ${ }^{[29]}$ In a recently published animal study, apposition was more important than pore density as a predictor of aneurysm occlusion after flow diversion. ${ }^{[30]}$ These data are clinically supported by the SCENT study which is a multi-center, prospective, non-randomized clinical study performed in 213 subjects. In this study, the total occlusion and residual aneurysm rates (Raymond-Roy grade 1 and 3) for optimally apposed and malapposed devices-based on core laboratory evaluation-were 79.2 versus $50 \%$ and 9.6 versus $41.2 \%$. ${ }^{[26]}$ This very striking difference shows the fundamental role of better apposition in the efficacy of the flow diverters. Suboptimal device apposition is not infrequent with braided devices at arterial bends, which leads to insufficient support and intimal overgrowth of the aneurysm neck due to lower metallic coverage. ${ }^{[16,31]}$ Apposition is critical not only for occlusion rates, but it also decreases that the rate of thromboembolic complications. ${ }^{[7,14,21]}$ Incomplete apposition of the flow diverter to the vessel wall may cause distal embolic complications or delayed occlusions, even if the stenosis is not flow limiting. ${ }^{[14,21]} \mathrm{Six}$ of the 7 malapposed flow diverters showed parent artery occlusion in a previous 
study ${ }^{[4]}$ and in another experimental comparative study, correction of flow diverter malapposition in rabbits resulted in a statistically significant improvement in aneurysm occlusion rates. ${ }^{[21]}$ It was also shown that incomplete stent apposition to the arterial wall can delay endothelial coverage of stent struts. ${ }^{[32,33]}$ However, even after balloon angioplasty of flow diverters, there may be residual malapposition, ${ }^{[10]}$ which may be present in up to $1 / 3$ of cases and may be detectable only with advanced imaging such as optical coherence tomography. ${ }^{[21]}$ Although routine angioplasty of flow diverters may be considered given the difficulties of delineating all of the malappositions, animal research has shown that angioplasty in a properly apposed flow diverter may lead to malapposition and thus may be detrimental. ${ }^{[2]}$ Balloon angioplasty of the flow diverter was also shown to cause microthrombi formation along the device as well as distal embolization, and it may lead to excessive flow diverter shortening with consequent migration of the device into the aneurysm. ${ }^{[15,34]}$ Finally, balloon angioplasty may not be effective for apposition of flow diverters when landing zones are at arterial bends. ${ }^{[17]}$

The EFT technique we describe is unique to the SFD, which tends to demonstrate a higher rate of malapposition at the expense of a high mesh density and a subsequent high rate of aneurysm occlusion. ${ }^{[35]}$ The rate of use of adjunctive devices for better placement or apposition of the Surpass device was reported to be as high as $42 \%$ in the literature. ${ }^{[35]}$ This possibly relates to the relatively bulky delivery system and the relatively stiffer device, which may result in intraprocedural findings-as listed above-that may necessitate the use of a stent or other adjunctive devices. The advantage of our technique is that it is quick and easy to perform and at least in our series, it did not result in neurologic morbidity. Our method has some technical advantages. First, it precludes the need to re-cross the flow diverter, which can potentially cause foreshortening or migration. Furthermore, especially if a larger stent is to be used to salvage device prolapse or foreshortening, an exchange maneuver will be needed for the larger microcatheters dedicated to these stents, increasing the risk of distal wire perforation. It is straightforward since the $2 \mathrm{~F}$ inner catheter is already distal to the SFD once the device is deployed and the stent is deployed directly through this inner catheter, in a single step. This is associated with a decrease in the fluoroscopy time and the overall procedure time compared to placement of a balloon catheter or another flow diverter for better flow diverter apposition. Finally, placement of a laser cut stent also precludes fish-mouth formation during follow-up, which is a drawback, exclusively of the braided stent design.

The 5 conditions that prompted us to use EFT, as listed in the previous section, generally apply to large and fusiform aneurysms and to those aneurysms located close to arterial bends (e.g., carotid siphon). Such aneurysms tend to be complex aneurysms. Small aneurysms located on relatively straight segments are less likely to need EFT.

Laser-cut mini stents have a higher radial force compared to flow diverters and consequently enable better flow diverter wall apposition. ${ }^{[10,15]}$ We speculate that this translated into a higher occlusion rate in our series. Complete occlusion rates of commonly used flow diverters are reported to be around $66.6 \%-75 \%$ at 6 months. ${ }^{[1,3-6]}$ Our technique was associated with a complete occlusion rate of $82.1 \%$ at 6 months and $95.2 \%$ at 9-12 months. Only one patient had residual filling at the end of 1 year due to suboptimal deployment of the flow diverter. Since the flow diverter foreshortened much more than we expected, the fusiform aneurysm remained only partially covered by the FD in its proximal segment. In the single case of failure of EFT, we tried to use an Acclino stent. None of those we treated with the Atlas stent resulted in failure. This may be due to the better flexibility of the latter stent. ${ }^{[36]}$ In addition, due to the open-cell design of this stent, we believe it results in better wall apposition.

There are some drawbacks of this technique and we suggest that it should be limited only to those cases that need further endovascular manipulation to address an existing or potential problem with the deployment or apposition of the SFD such as those listed above in the previous section. The major disadvantages of the technique are cost and placement of an additional metallic device in the intracranial arteries that may become an issue in patients with recent subarachnoid hemorrhage. Cost is certainly an important issue when we compare the cost of a case treated with straightforward flow diversion to a case treated with EFT. However, this technique compares well with other adjunctive methods used for flow diversion. For instance, some authors prefer to perform coiling of the aneurysm sac to achieve occlusion rates as high as ours. Dense coiling is associated with increased cost and may also be associated with thrombus migration, occlusion of the flow diverter or mass effect. ${ }^{[37]}$ In addition, some practitioners prefer to place telescopic flow diverters. A systematic review of flow diversion for intracranial aneurysms revealed that more than one diverter was used in $27 \%$ of the cases. ${ }^{[38]}$ Similarly, in the PUFS trial, the number of flow diverters placed per aneurysm was three. ${ }^{[5]}$ In another study using a single type of flow diverter, 63 of 77 aneurysms were treated with multiple flow diverters. ${ }^{[4]}$ The mini-stents were used in this study are cheaper than flow diverters so the cost increase in our technique appears acceptable in comparison to telescoping flow diverters. The cost increase related to EFT is higher than balloon angioplasty which was used in as much as $42 \%$ of the cases in a recent study. ${ }^{[35]}$ On the other hand, as discussed in detail above, balloon angioplasty is not an ideal a solution in situations for which this technique was used. As for the issue of increase the metallic ratio of the scaffold, it is probable that in patients with subarachnoid hemorrhage, additional 
placement of the stent may exacerbate a thrombotic event. In such cases, potential benefits and side effects of EFT should be considered in detail.

This study has a number of limitations. It is a retrospective study with a relatively small number of patients. In addition, due to the absence of a control arm, we certainly favor the use of this technique in selected situations, as listed in the results section, rather than routinely. Finally, neither the mini stents we used, nor the delivery system of the flow diverter is approved for this technique. Thus, the technique is an off-label use for both of these devices.

\section{Conclusion}

The use of the inner catheter of the SFD to deploy laser cut stents to enhance wall apposition of this device was associated with a high and relatively early complete occlusion of the aneurysms. This EFT was simple to perform, safe and effective in our series. Although this technique may be used to improve the results of the Surpass device in selected situations, routine use of this technique cannot be recommended based on this study. We suggest that its use should be limited to those cases with imminent or potential problems related to the deployment or apposition of the SFD.

\section{Financial support and sponsorship}

Nil.

\section{Conflicts of interest}

There are no conflicts of interest.

\section{References}

1. Akgul E, Onan HB, Akpinar S, Balli HT, Aksungur EH. The DERIVO embolization device in the treatment of intracranial aneurysms: Short-and midterm results. World Neurosurg 2016;95:229-40.

2. Drescher F, Weber W, Berlis A, Rohde S, Carolus A, Fischer S. Treatment of intra-and extracranial aneurysms using the flow-redirection endoluminal device: Multicenter experience and follow-up results. AJNR Am J Neuroradiol 2017;38:105-12.

3. Möhlenbruch MA, Herweh C, Jestaedt L, Stampfl S, Schönenberger S, Ringleb PA, et al. The FRED flow-diverter stent for intracranial aneurysms: Clinical study to assess safety and efficacy. AJNR Am J Neuroradiol 2015;36:1155-61.

4. Berge J, Biondi A, Machi P, Brunel H, Pierot L, Gabrillargues J, et al. Flow-diverter silk stent for the treatment of intracranial aneurysms: 1-year follow-up in a multicenter study. AJNR Am J Neuroradiol 2012;33:1150-5

5. Becske T, Kallmes DF, Saatci I, McDougall CG, Szikora I, Lanzino G, et al. Pipeline for uncoilable or failed aneurysms: Results from a multicenter clinical trial. Radiology 2013;267:858-68.

6. Wakhloo AK, Lylyk P, de Vries J, Taschner C, Lundquist J, Biondi A, et al. Surpass flow diverter in the treatment of intracranial aneurysms: A prospective multicenter study. AJNR Am J Neuroradiol 2015;36:98-107.

7. Kühn AL, Rodrigues KM, Wakhloo AK, Puri AS. Endovascular techniques for achievement of better flow diverter wall apposition. Interv Neuroradiol 2019;25:344-7.

8. Lescher S, du Mesnil de Rochemont R, Berkefeld J. Woven Endobridge (WEB) device for endovascular treatment of complex unruptured aneurysms-a single center experience. Neuroradiology 2016;58:383-90.

9. Nossek E, Chalif DJ, Chakraborty S, Lombardo K, Black KS, Setton A. Concurrent use of the Pipeline Embolization Device and coils for intracranial aneurysms: Technique, safety, and efficacy. J Neurosurg 2015;122:904-11.

10. Kühn AL, Wakhloo AK, Gounis MJ, Kan P, de Macedo Rodrigues K, Lozano JD, et al. Use of self-expanding stents for better intracranial flow diverter wall apposition. Interv Neuroradiol 2017;23:129-36.

11. Amuluru K, Al-Mufti F, Roth W, Prestigiacomo CJ, Gandhi CD. Anchoring pipeline flow diverter construct in the treatment of traumatic distal cervical carotid artery injury. Interv Neurol 2017;6:153-62.

12. Rahal JP, Dandamudi VS, Heller RS, Safain MG, Malek AM. Use of concentric Solitaire stent to anchor Pipeline flow diverter constructs in treatment of shallow cervical carotid dissecting pseudoaneurysms. J Clin Neurosci 2014;21:1024-8.

13. Ocal O, Peker A, Balci S, Arat A. Placement of a stent within a flow diverter improves aneurysm occlusion rates. AJNR Am J Neuroradiol 2019;40:1932-8.

14. Estrade L, Makoyeva A, Darsaut TE, Ghostine J, Kouznetsov E, Salazkin I, et al. In vitro reproduction of device deformation leading to thrombotic complications and failure of flow diversion. Interv Neuroradiol 2013;19:432-7.

15. Srinivasan VM, Carlson AP, Mokin M, Cherian J, Chen SR, Puri A, et al. Prolapse of the Pipeline embolization device in aneurysms: Incidence, management, and outcomes. Neurosurg Focus 2017;42:E16.

16. Kim BM, Shin YS, Baik MW, Lee DH, Jeon P, Baik SK, et al. Pipeline embolization device for large/giant or fusiform aneurysms: An initial multi-center experience in Korea. Neurointervention 2016;11:10-7.

17. Shapiro M, Becske T, Nelson PK. Learning from failure: Persistence of aneurysms following pipeline embolization. J Neurosurg 2017;126:578-85.

18. Brinjikji W, Murad MH, Lanzino G, Cloft HJ, Kallmes DF. Endovascular treatment of intracranial aneurysms with flow diverters: A meta-analysis. Stroke 2013;44:442-7.

19. Zhou G, Su M, Zhu YQ, Li MH. Efficacy of flow-diverting devices for cerebral aneurysms: A systematic review and meta-analysis. World Neurosurg 2016;85:252-62.

20. Chow M, McDougall C, O'Kelly C, Ashforth R, Johnson E, Fiorella D. Delayed spontaneous rupture of a posterior inferior cerebellar artery aneurysm following treatment with flow diversion: A clinicopathologic study. AJNR Am J Neuroradiol 2012;33:E46-51.

21. King RM, Brooks OW, Langan ET, Caroff J, Clarençon F, Tamura T, et al. Communicating malapposition of flow diverters assessed with optical coherence tomography correlates with delayed aneurysm occlusion. J Neurointerv Surg 2018;10:693-7.

22. Rouchaud A, Ramana C, Brinjikji W, Ding YH, Dai D, Gunderson T, et al. Wall apposition is a key factor for aneurysm occlusion after flow diversion: A histologic evaluation in 41 rabbits. AJNR Am J Neuroradiol 2016;37:2087-91.

23. van der Marel K, Gounis MJ, Weaver JP, de Korte AM, King RM, Arends JM, et al. Grading of regional apposition after flow-diverter treatment (GRAFT): A comparative evaluation of VasoCT and intravascular OCT. J Neurointerv Surg 2016;8:847-52. 
24. Aguilar Pérez M, Bhogal P, Henkes E, Ganslandt O, Bäzner H, Henkes H. In-stent stenosis after p64 flow diverter treatment. Clin Neuroradiol 2018;28:563-8.

25. Kraus B, Goertz L, Turowski B, Borggrefe J, Schlamann M, Dorn F, et al. Safety and efficacy of the Derivo Embolization Device for the treatment of unruptured intracranial aneurysms: A multicentric study. J Neurointerv Surg 2019;11:68-73.

26. Meyers PM, Coon AL, Kan PT, Wakhloo AK, Hanel RA. SCENT Trial. Stroke 2019;50:1473-9.

27. Kaya T, Daglioglu E, Gurkas E, Akmangit I, Peker A, Belen D, et al. Silk device for the treatment of intracranial aneurysms, part 2: Factors related to clinical and angiographic outcome. Turk Neurosurg 2016;26:533-7.

28. Peker A, Akgul E, Daglioglu E, Akmangit I, Kaya T, Belen D, et al. Tapered flow diverters in the treatment of intracranial aneurysms. Turk Neurosurg 2017;27:863-6.

29. Anzai H, Falcone JL, Chopard B, Hayase T, Ohta M. Optimization of strut placement in flow diverter stents for four different aneurysm configurations. $J$ Biomech Eng 2014;136:061006

30. Aquarius R, de Korte A, Smits D, Gounis M, Verrijp K, Driessen L, et al. The Importance of Wall Apposition in Flow Diverters. Neurosurgery 2019;84:804-10.

31. Shapiro M, Raz E, Becske T, Nelson PK. Variable porosity of the pipeline embolization device in straight and curved vessels: A guide for optimal deployment strategy. AJNR Am J Neuroradiol 2014;35:727-33.

32. Foin N, Gutiérrez-Chico JL, Nakatani S, Torii R, Bourantas CV, Sen $\mathrm{S}$, et al. Incomplete stent apposition causes high shear flow disturbances and delay in neointimal coverage as a function of strut to wall detachment distance: Implications for the management of incomplete stent apposition. Circ Cardiovasc Interv 2014;7:180-9.

33. Kim JS, Ha J, Kim BK, Shin DH, Ko YG, Choi D, et al. The relationship between post-stent strut apposition and follow-up strut coverage assessed by a contour plot optical coherence tomography analysis. JACC Cardiovasc Interv 2014;7:641-51.

34. Marosfoi M, Clarencon F, Langan ET, King RM, Brooks OW, Tamura $\mathrm{T}$, et al. Acute thrombus formation on phosphorilcholine surface modified flow diverters. J Neurointerv Surg 2018;10:406-11.

35. Colby GP, Lin LM, Caplan JM, Jiang B, Michniewicz B, Huang $\mathrm{J}$, et al. Flow diversion of large internal carotid artery aneurysms with the surpass device: Impressions and technical nuance from the initial North American experience. J Neurointerv Surg 2016;8:279-86.

36. Cay F, Peker A, Arat A. Stent-assisted coiling of cerebral aneurysms with the Neuroform Atlas stent. Interv Neuroradiol 2018;24:263-9.

37. Siddiqui AH, Kan P, Abla AA, Hopkins LN, Levy EI. Complications after treatment with pipeline embolization for giant distal intracranial aneurysms with or without coil embolization. Neurosurgery 2012;71:E509-13.

38. Briganti F, Leone G, Marseglia M, Mariniello G, Caranci F, Brunetti A, et al. Endovascular treatment of cerebral aneurysms using flow-diverter devices: A systematic review. Neuroradiol J 2015;28:365-75. 


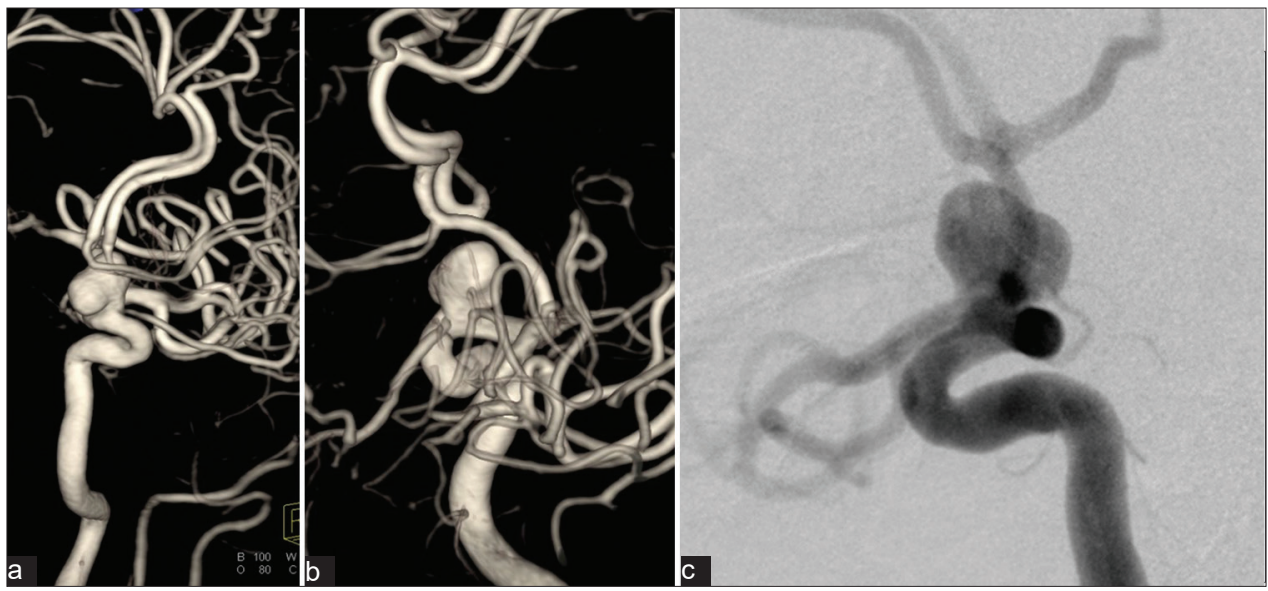

Figure 1: Supplemental digital content 1. Three-dimensional angiograms obtained from rotational angiogram (a and b) and left carotid arteriogram (c) in working projection show an ophthalmic aneurysm
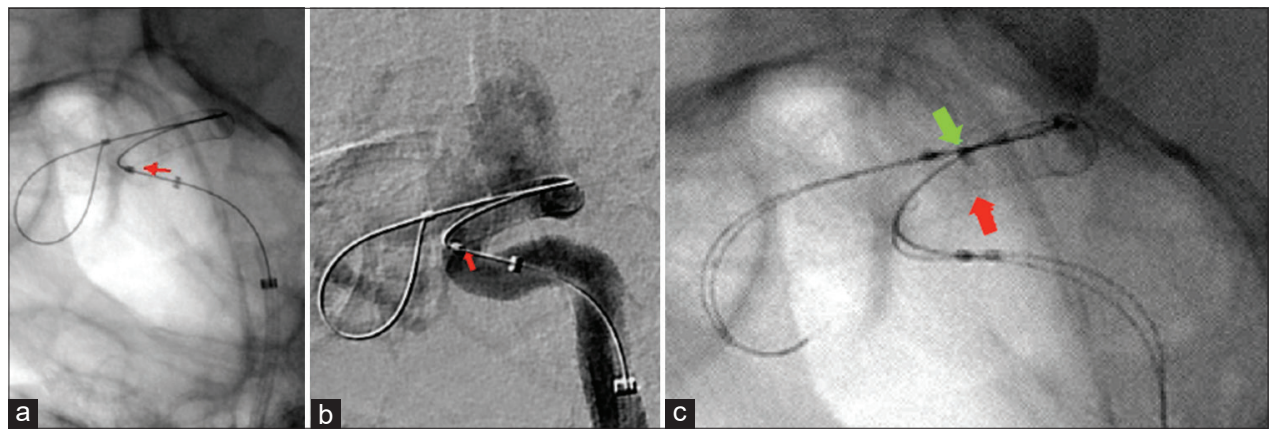

Figure 2: Supplemental digital content 1. Intraprocedural images in working projection in native (a) and subtracted (b) views just after deployment of the Surpass device show that the proximal end of the device is not apposed to the arterial wall inferiorly [red arrow, there was also distal device malapposition as noted in Figure 3]. Fluoroscopic capture in the same projection (c). After deployment, as the slack of the inner catheter was removed and slight backward tension was applied to remove the inner catheter, the outer catheter moved forward over the inner catheter beyond our control and got entangled with the proximal end of the device (green arrow), pushing it distally and resulting in foreshortening

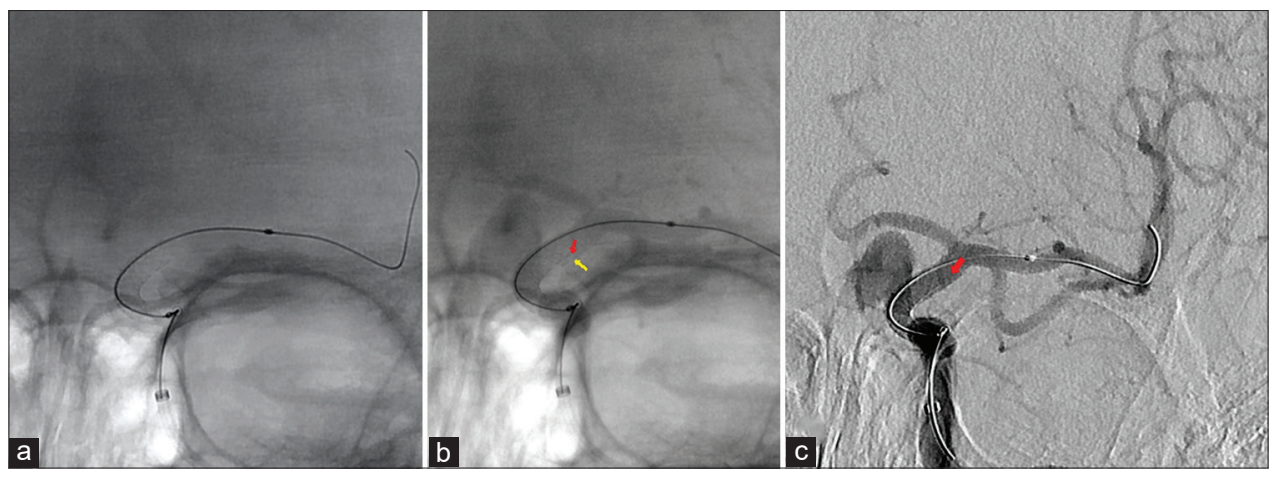

Figure 3: Supplemental digital content 1. Native images before (a) and after (b) contrast injection and subtracted image (c) in working projection just after device deployment revealed some malapposition at the distal end as well (red arrow denotes the outline of the device, yellow arrows mark the arterial wall) 


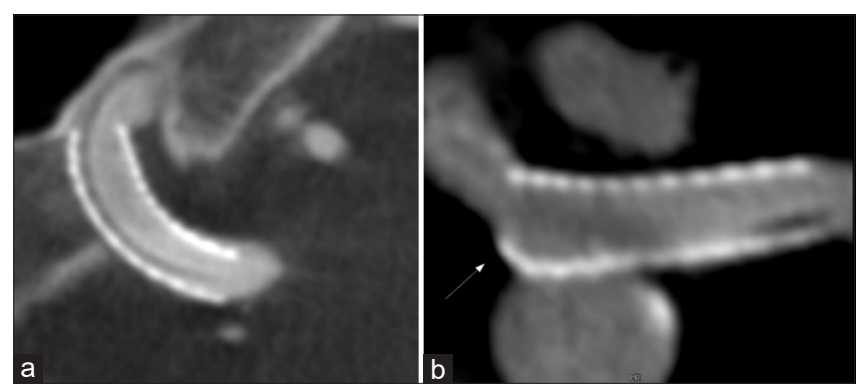

Figure 4: Supplemental digital content 1 . When device foreshortening was noted, a flat panel computed tomography with intra-arterial contrast injection was obtained immediately to determine this resulted in further deployment problems. (a) Reformatted image shows malapposition of the device at its distal end. Note the inner catheter parallel to the medial wall of the device as a hypodense tubular structure. (b) The proximal end of the device shows subtle prolapse of the device into the aneurysm and the proximal landing zone is very short (white arrow)

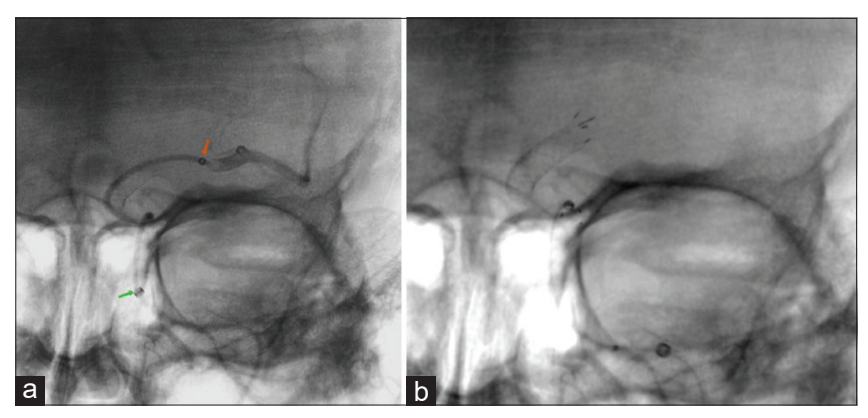

Figure 5: Supplemental digital content 1. (a) Without re-crossing the stent, the outer catheter was pulled gently even further back over the inner catheter. A superselectiveangiogram was obtained through the inner catheter (orange arrow denotes the tip of the catheter) to make sure it is within MCA and not a perforator. Green arrow shows distal end of the outer catheter. (b) An atlas stent was deployed through the inner catheter
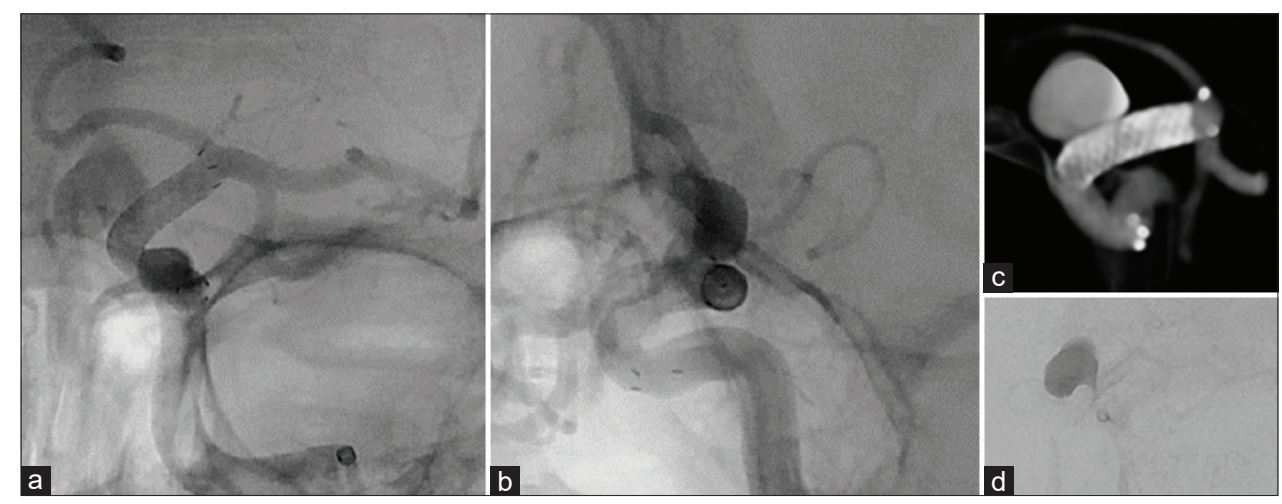

Figure 6: Supplemental digital content 1. Native views in working projection (a and b) and reformatted flat panel computed tomography image (c) after intra-arterial contrast injection obtained after stent deployment through the inner catheter show good apposition and pinning of the flow diverter by the Atlas stent. The subtle prolapse of the flow diverter at its proximal end as noted in Figure 4 is no longer visible. (d) Angiogram in delayed arterial phase in working projection (A plane) shows significant contrast stagnation in aneurysm after stent deployment 


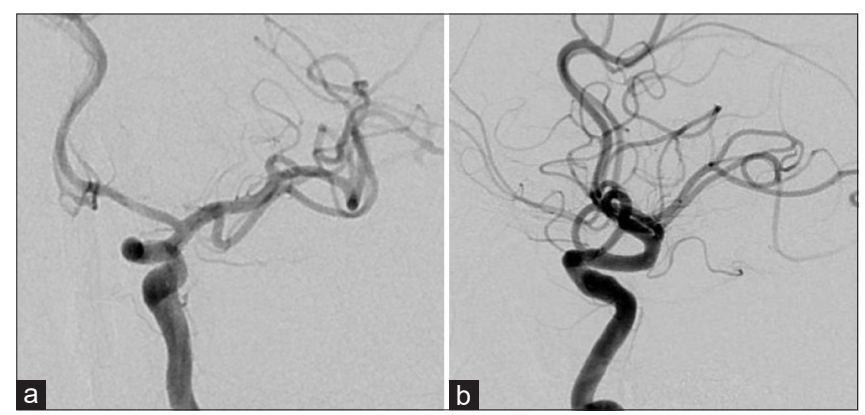

Figure 7: Supplemental digital content 1. Six-month follow-up angiogram ( $a$ and $b$ ) shows total occlusion of the aneurysm and patency of the stent construct
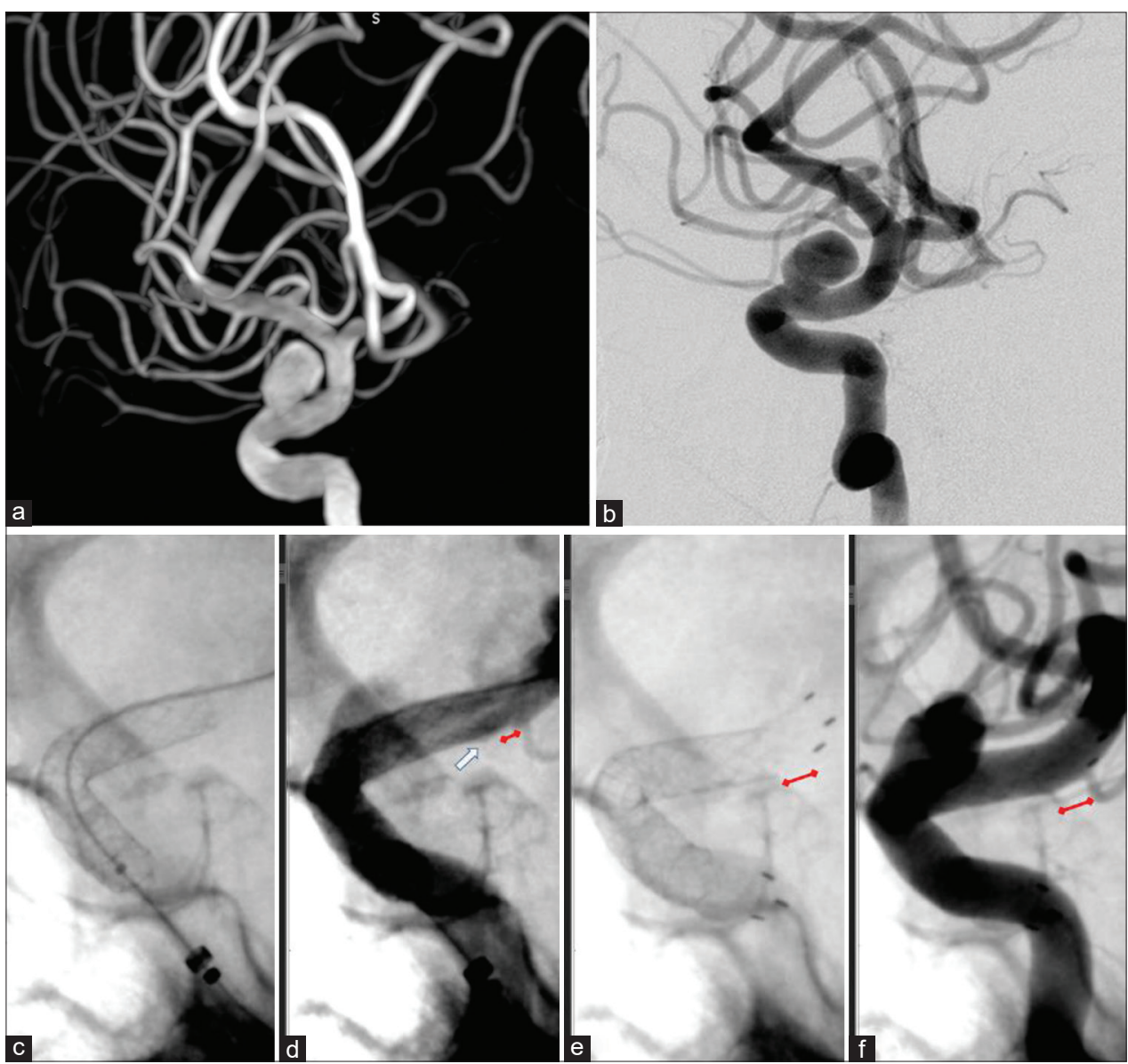

Figure 1: Supplemental digital content 2. Left carotid arteriogram shows an ophthalmic artery aneurysm (a) three-dimensional images in maximum intensity projection and (b) digital subtraction angiography image in working projection. (c and d) Native images of digital subtraction angiography obtained after placement of the Surpass device delineate a small malapposed segment at the origin of a hypoplastic posterior communicating artery (white arrow). Note the expansion and foreshortening of the device once the Atlas stent is deployed (e and $f$ ). The red line indicates the distance between the tip of the device and the anterior choroidal artery. The distance is longer in $\mathrm{E}$ and $\mathrm{F}$ attesting to a foreshortening of approximately $1 \mathrm{~mm}$, the device now lies proximal to the posterior communicating artery. The supplementary video shows the deployment of this stent 

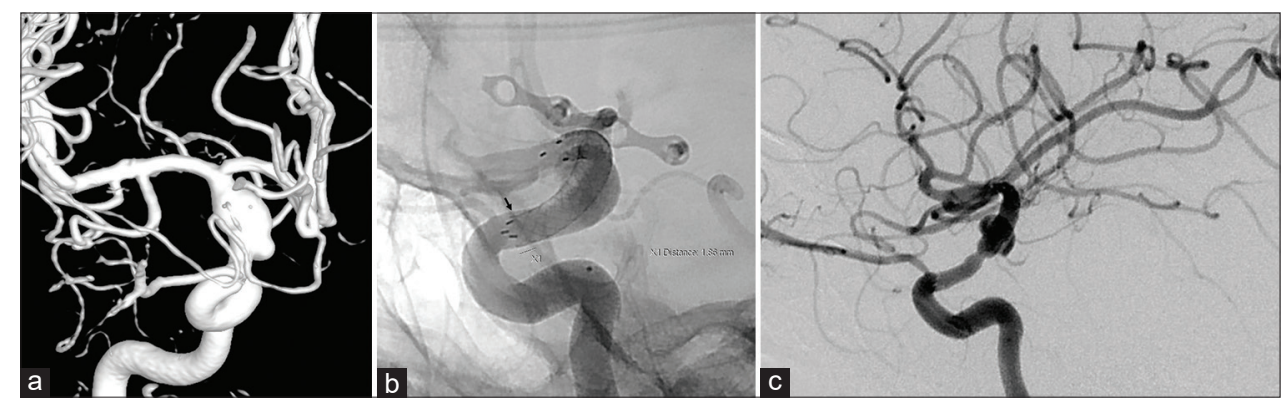

Figure 2: Supplemental digital content 2. (a) Three-dimensional view of a right internal carotid artery fusiform supraclinoid aneurysm which appeared on follow-up imaging after pituitary surgery. (b) Angiogram after deployment the flow diverter and then an Atlas stent shows malapposition (arrow) and incomplete coverage of the fusiform aneurysm proximally, the landing zone of the diverter is about $1 \mathrm{~mm}$ which is far less than the recommended length for the landing zone. (c) Follow-up angiogram obtained 6 months after the procedure shows residual opacification of the aneurysm and mild in stent stenosis. There is no residual malapposition of the flow diverter
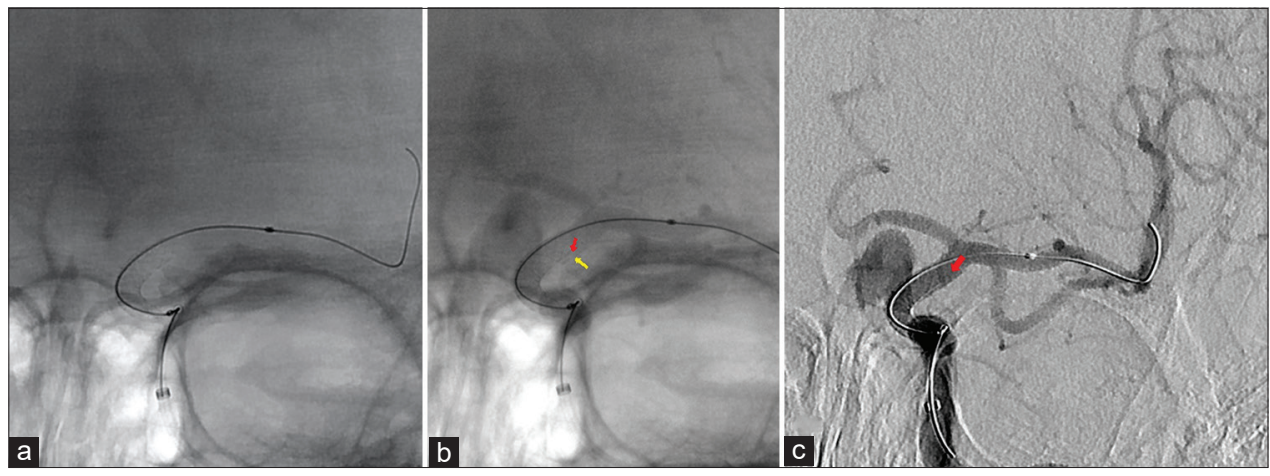

Figure 3: Supplemental digital content 2. (a) Right internal carotid artery angiogram shows an ophthalmic segment aneurysm. (b) Native image of the carotid angiogram after the deployment of the flow diverter demonstrates suboptimal apposition of the device at the distal landing zone immediately distal to the cavernous bend, the distal segment of the FD remained malapposed and ends just at the origin of the posterior communicating artery (arrow). (c) Angiogram after the deployment of a stent inside the flow diverter shows good apposition of the device to the parent artery and further foreshortening of the device

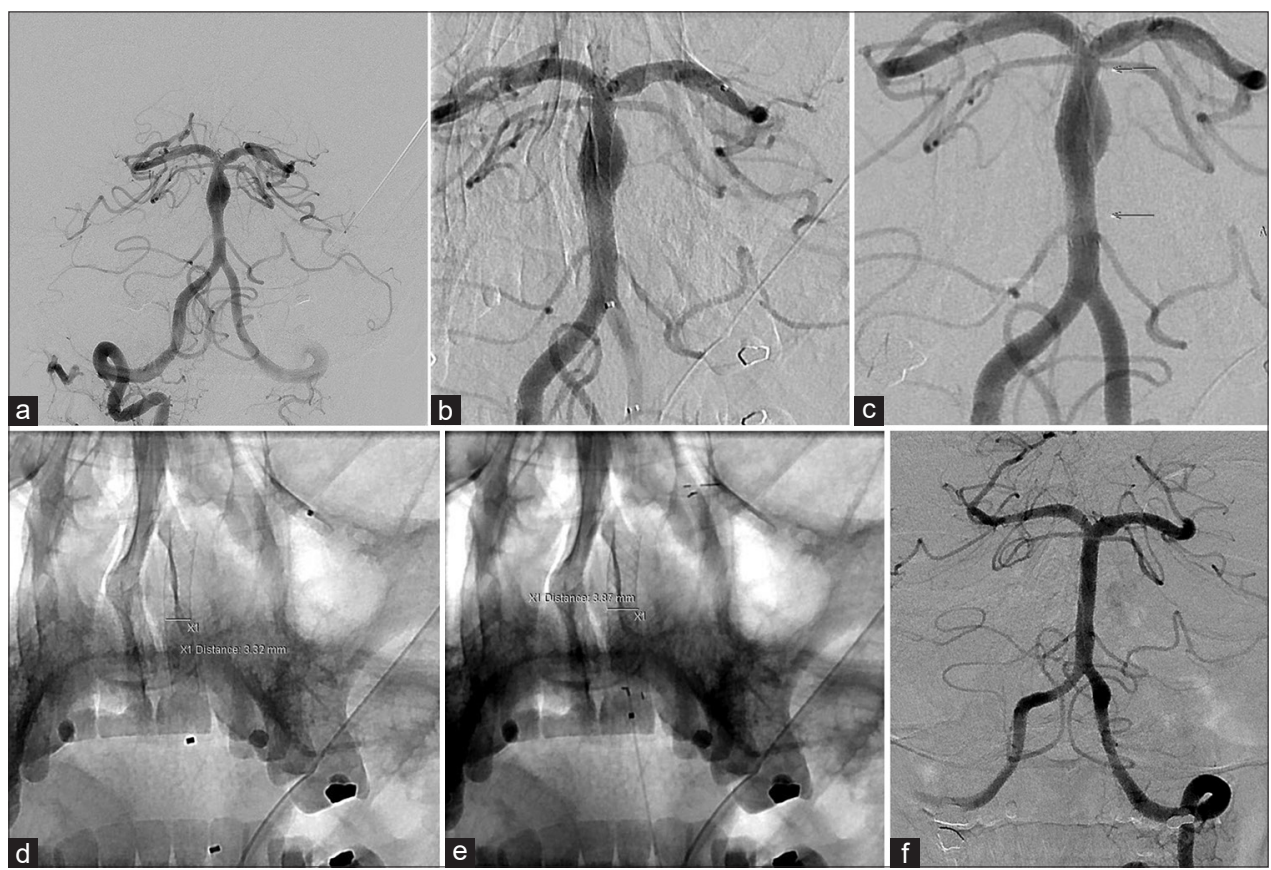

Figure 4: Supplemental digital content 2. (a) Right vertebral artery angiogram demonstrates a fusiform basilar trunk aneurysm in a patient with acute subarachnoid hemorrhage. (b) The Surpass device jailed the origin of the right superior cerebellar artery (SCA) and protruded into the origin of the left SCA. (c) An Atlas stent was deployed inside the flow diverter, foreshortening the Surpass device and unjailing of both SCAs and posterior inferior cerebellar arteries, arrows point to the distal and proximal ends of the FD after apposition. (d-e) Plain radiographs before (d) and after (e) the deployment of the stent shows a further $0.5 \mathrm{~mm}$ expansion of the flow diverter. Foreshortening of the device is also appreciated also when bony landmarks are used as reference. (f) Follow-up angiogram obtained 4 months after the procedure shows complete occlusion of the aneurysm and patency of both SCAs 


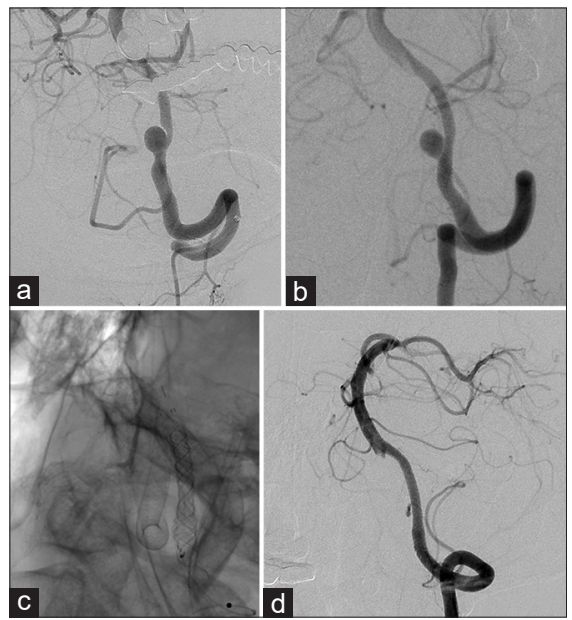

Figure 5: Supplemental digital content 2. (a) Digital subtraction angiography demonstrating a PICA aneurysm on the left side. (b) Follow-up angiogram obtained 43 months after placement of the first and 24 months after the placement of the second nitinol FD reveals residual filling of the aneurysm. (c) Plain radiograph at the end of the third procedure (placement of a Surpass device and an Atlas stent inside the previously deployed flow diverters). Another Surpass device had been placed for the treatment of a smaller mirror aneurysm of the distal right vertebral artery. (d) Follow-up angiogram obtained 6 months after the third procedure shows complete occlusion of the aneurysm and stenosis of the PICA that comes off the aneurysm 